\title{
Two Causes of Demyelinating Neuropathy in One Patient: CMT1A and POEMS Syndrome
}

\author{
Nizar Chahin, Steven R. Zeldenrust, Kimberly K. Amrami, JaNean K. Engelstad, \\ P. James B. Dyck
}

Can. J. Neurol. Sci. 2007; 34: 380-385

In most cases, there is only one cause for a patient's peripheral neuropathy (e.g. diabetes mellitus, uremia, inflammatory demyelination, vasculitic, inherited or other). However, occasionally more than one cause may be present and clinically important. The case illustrated here shows that inherited (CMT1A) and acquired (POEMS) demyelinating neuropathies can coexist and both contribute to the clinical presentation of a neuropathy. Charcot-Marie-Tooth 1A (CMT1A) is an autosomal dominant inherited neuropathy with insidious progression over years with disability due to distal- and motor-predominant dysfunction. It usually presents before age $20,{ }^{1}$ but it can also present later in life. There is usually uniform slowing of conduction velocities with little temporal dispersion or conduction block. Both the presence of paresthesias, which are unusual in $\mathrm{CMT}_{1} \mathrm{~A}^{2}$ and acute worsening in an otherwise gradually progressive condition such as CMT1A, should alert the clinician to the presence of a second and possibly treatable form of peripheral neuropathy. POEMS syndrome is defined ${ }^{3,4}$ by the presence of Polyneuropathy (P), Organomegaly (O), Endocrinopathy $(\mathrm{E}), \mathrm{M}$ protein $(\mathrm{M})$ and Skin changes $(\mathrm{S})$. In POEMS syndrome, peripheral neuropathy is frequently the presenting manifestation and it can be rapidly progressive. It is usually symmetric and distal predominant but proximal limb segments are often involved. It can be very severe and usually has both axonal and demyelinating features on electrodiagnostic studies. Most patients have sclerotic bone lesions from osteosclerotic myeloma or have Castleman's disease. POEMS syndrome is a potentially treatable disorder.

\section{Case Report}

A 59-year-old man with a family history of CMT1A (in his father, two brothers and a sister) developed tingling and loss of feeling in his feet 13 months prior to our evaluation. Up to this time he was a vigorous, healthy man who played tennis regularly and had no known neurological deficits. Two months after the onset of symptoms, he sought neurological evaluation locally and had nerve conduction studies and electromyography (Table 1) that were felt to be consistent with inherited demyelinating neuropathy. Genetic testing confirmed PMP22 duplication and he was diagnosed with CMT1A. Over time, he developed prominent neuropathic sensory symptoms (numbness and prickling) of his finger tips, lips and nose but without development of associated pain. Simultaneously, he developed rapid weakness that started distally, spread proximally and was worse in his lower than his upper extremities. He was wheelchair dependent within one year. On review of symptoms, he reported no sphincter or autonomic dysfunction and no bulbar involvement. He had lost 20 pounds of weight. Because of a borderline low normal B12 level, he had received monthly B12 injections, and he was taking Furosemide for lower extremity edema. He had partial thyroidectomy as a teenager and had mild hyperlipidemia.

On examination, he had pes cavus and pitting edema of feet and legs and hypertrichosis. No organomegaly or abnormal skin pigmentation was seen. Mental status and cranial nerve examination were normal. He had diffuse weakness in upper and lower limbs, moderate in proximal muscles (4/5 in MRC) and severe (0 to 3/5 in MRC) in distal muscles. He was areflexic and had pan-modality sensory loss (to touch, pin, temperature, vibration, and joint position sense) in a stocking and glove distribution with pseudoathetosis of the fingers. His Neuropathy Impairment Score (a global score of weakness, reflex loss and sensory loss) was 121.5 (a very severe peripheral neuropathy). ${ }^{5}$

A familial neuropathy had been identified 20 years earlier when the patient's father and brother had been diagnosed with CMT1 at our institution based on clinical and electrophysiological (demyelinating) criteria. He has two affected brothers and one affected sister. There were multiple family members with neuropathy, high arches, or tremor (Figure 1).

The following laboratory tests were normal: complete blood count (CBC), erythrocyte sedimentation rate (ESR), B12, folic acid, vitamin $\mathrm{E}$, hemoglobin A1c (HbA1C), aspartate aminotransferase (AST), angiotensin converting enzyme (ACE), free thyroxin, prolactin, luteinizing hormone ( $\mathrm{LH})$, follicle stimulating hormone (FSH), anti-nuclear antibody (ANA), extractable nuclear antigens (ENA), anti-neutrophil cytoplasmic antibody (ANCA), rheumatoid factor (RF), paraneoplastic antibodies, Lyme titer by ELISA, hepatitis profile, human immunodeficiency virus (HIV) serology, copper, zinc, heavy

From the Department of Neurology (NC, JNKE, PJBD), Department of Hematology (SRZ), Department of Radiology (KKA), Mayo Clinic College of Medicine, Rochester, Minnesota, USA.

RECEIVED FEBRUARY 1, 2007. ACCEPTED IN FINAL FORM APRIL 16, 2007. Reprint requests to: P. James B. Dyck, Mayo Clinic, Department of Neurology, 200 First Street SW, Rochester, Minnesota, USA, 55905. 
Table 1: Nerve conduction studies early in the disease course

\begin{tabular}{llll}
\hline Stimulate (Record) & $\begin{array}{l}\mathrm{A} \\
(\mathrm{mV} / \mu \mathrm{V})\end{array}$ & $\mathrm{CV}(\mathrm{m} / \mathrm{s})$ & $\mathrm{DL}(\mathrm{ms})$ \\
R Median motor (APB) & $4.3(>4.5)$ & $13(>48)$ & $11.4(<4.4)$ \\
R Tibial motor (AH) & $0.4(>5.4)$ & $11(>40)$ & $10.6(<6.6)$ \\
L Tibial motor (AH) & $0.2(>5.4)$ & $12(>40)$ & $9.9(<6.6)$ \\
R Sural sensory (Ankle) & 0 & -- & $\mathrm{NR}$ \\
L Sural sensory (Ankle) & 0 & -- & $\mathrm{NR}$ \\
\hline
\end{tabular}

metal screen and urine screen for monoclonal proteins. His fasting plasma glucose $(119 \mathrm{mg} / \mathrm{dL})(70-100)$ and his thyroid stimulating hormone (TSH) $(6.4 \mathrm{mIU} / \mathrm{L})(0.30-5)$ were mildly elevated whereas his total testosterone of $67 \mathrm{ng} / \mathrm{dL}$ (240-950) was reduced. He had a small monoclonal IgA Lambda on his serum protein monoclonal immunofixation study. Because of concern for POEMS syndrome, we obtained a vascular endothelial growth factor (VEGF) level that was elevated at 366 $\mathrm{pg} / \mathrm{ml}$ (normal 31-66). Cerebral spinal fluid (CSF) analysis showed raised opening pressure of $250 \mathrm{~mm} \mathrm{H}_{2} \mathrm{O}$, a protein of $146 \mathrm{mg} / \mathrm{dl}$ (14-45) and normal or negative CSF tests of glucose, cell count, IgG synthesis rate, lyme, VDRL and cytology.

Metastatic skeletal X-rays showed sclerotic lesions in the right transverse process of the first thoracic bone and the left neck and body of the scapula. A CT scan showed additional sclerotic lesions in the left occipital bone and an enlarged left axillary lymph node (Figure 2). A 3-tesla MRI of the lumbosacral plexus demonstrated an increased size and hyperintensity of portions of the lumbosacral plexus with markedly enlarged L4 and L5 nerve roots and mild to moderate contrast enhancement.

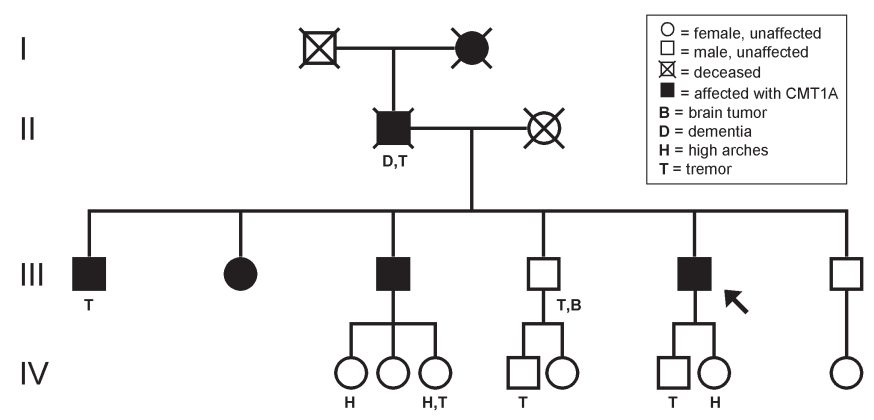

Figure 1. The family history demonstrating autosomal dominant inheritance of CMT1A. Note multiple family members had high arches, tremor or both.
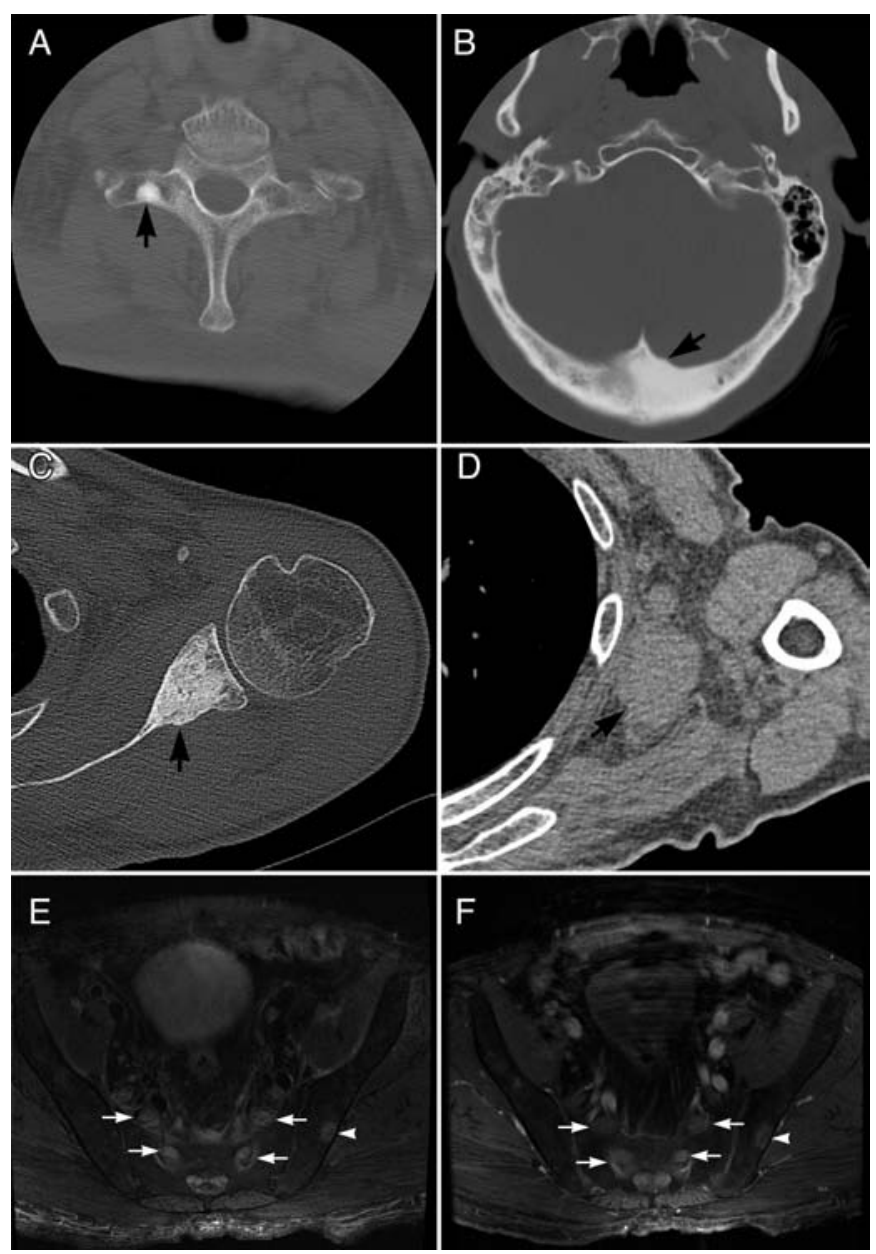

Figure 2. Radiological imaging (CT and MRI) from our patient with CMT1A and POEMS syndrome. CT imaging shows multiple osteosclerotic lesions in the right transverse process of $T 1(A)$, left occipital bone (B), neck and adjacent body of the left scapula $(C)$ and an enlarged left axillary lymph node $(D)$. MRI of the pelvis shows $(E)$ enlargement and increased T2 signal in the nerves of the lumbosacral plexus (arrows). After intravenous gadolinium, T1 weighted imaging with fat suppression $(F)$ shows mild contrast enhancement within the nerves (arrows). Also noted was an area of enhancement within the left ileum (arrowheads) corresponding to a sclerotic lesion seen on CT.

The MRI also showed multiple enlarged pelvic lymph nodes and a sclerotic lesion within the left ilium (Figure 2).

Autonomic reflex screen showed marked cardiovagal and mild adrenergic impairments with preserved postganglionic sudomotor function. These findings suggested primary cardiac pathology. Subsequent echocardiogram showed findings compatible with chronic diastolic heart failure. Quantitative sensory testing showed elevation of vibration and cooling detection thresholds. Nerve conductions studies (Table 2) showed most of the motor and sensory responses to be absent. The two motor studies with preserved responses (ulnar and musculocutaneous) were of low amplitude and had very slowed conduction velocities and very prolonged distal latencies. The 
Table 2: Nerve conduction studies/EMG at evaluation

\begin{tabular}{llll} 
Nerve Conduction Study & & & \\
\hline Stimulate (Record) & $\mathrm{A}(\mathrm{mV} / \mu \mathrm{V})$ & $\mathrm{CV}(\mathrm{m} / \mathrm{s})$ & $\mathrm{DL}(\mathrm{ms})$ \\
\hline R Median sensory (Index) & $0(>15)$ & - & $\mathrm{NR}(<3.6)$ \\
R Musculocutaneous (BB) & 0.3 & 7 & 16.6 \\
R Ulnar motor (ADM) & $0.1(>6)$ & $8(>51)$ & $16.9(<3.6)$ \\
R Ulnar sensory (Fifth) & $0(>10)$ & -- & $\mathrm{NR}(<3.1)$ \\
R Peroneal motor (EDB) & $0(>2)$ & - & $\mathrm{NR}(<6.6)$ \\
R Peroneal motor (TA) & 0 & - & $\mathrm{NR}$ \\
R Tibial motor (AH) & $0(>4)$ & - & $\mathrm{NR}(<6.1)$ \\
R Sural sensory (Ankle) & $0(>6)$ & - & $\mathrm{NR}(4.5)$ \\
\hline
\end{tabular}

\begin{tabular}{lccc}
\multicolumn{1}{l}{ Trigeminal Blink Reflexes } & & \\
& \multicolumn{2}{c}{ Ipsilateral } & Contralateral \\
& $\mathrm{R} 1$ & $\mathrm{R} 2$ & $\mathrm{R} 2$ \\
\hline R Trigeminal supraorbital (OC) & $37.7(8-13)$ & $61.5(29-41)$ & $59.2(29-44)$ \\
\hline
\end{tabular}

\begin{tabular}{|c|c|c|c|c|c|}
\hline \multirow[t]{2}{*}{ Muscle } & \multirow{2}{*}{$\begin{array}{l}\text { Insertional } \\
\text { activity }\end{array}$} & \multirow[t]{2}{*}{ Fibrillation } & \multicolumn{3}{|c|}{ MUP } \\
\hline & & & Recruitment & Duration & Amplitude \\
\hline R Biceps brachii & Increased & $+/-$ & ++ & ++ & ++ \\
\hline R Deltoid & Normal & $+/-$ & ++ & + & + \\
\hline R FDI & Increased & ++ & +++ & + & + \\
\hline R Triceps brachii & Increased & + & ++ & ++ & + \\
\hline R Medial gastroc. & Increased & $+/-$ & ++++ & + & + \\
\hline R TFL & Increased & 0 & ++ & + & + \\
\hline $\mathrm{R}$ Tibialis anterior & Increased & + & ++++ & + & + \\
\hline$R$ Vastus medialis & Increased & + & t++ & ++ & + \\
\hline R Thoracic paraspinals & - & 0 & ++ & ++ & + \\
\hline R Paraspinal lumbar (upper) & - & 0 & ++ & ++ & ++ \\
\hline
\end{tabular}

trigeminal blink study had markedly prolonged R1 and R2 responses. Conduction block and temporal dispersion were not seen, although it is very hard to assess for these when the responses are so small. Needle EMG showed fibrillation potentials and markedly reduced recruitment of large motor unit potentials diffusely, including the lumbar and thoracic paraspinal muscles. These findings implied a longstanding, mixed axonal and demyelinating neurogenic disorder that is best described as a polyradiculoneuropathy (see Table 2 for details).

A left sural nerve biopsy showed severely decreased density of myelinated fibers in a diffuse pattern, an altered size distribution with selective loss of large fibers and thinly myelinated fibers, frequent large onion-bulbs in a generalized pattern (Figure 3), and an increased number of empty nerve strands. Several small collections of perivascular epineurial mononuclear inflammatory cells were seen. Smooth muscle actin preparations showed extensive neovascularization in the epineurium (Figure 3). A bone marrow biopsy was normal. A left axillary lymph node biopsy showed regressively transformed germinal centers with B-cells at the center and surrounded by Lambda light chain restricted plasma cells at the periphery of the germinal centers and in the interfollicular regions (Figure 4). These findings were felt to be consistent with plasma cell variant of Castleman's disease.

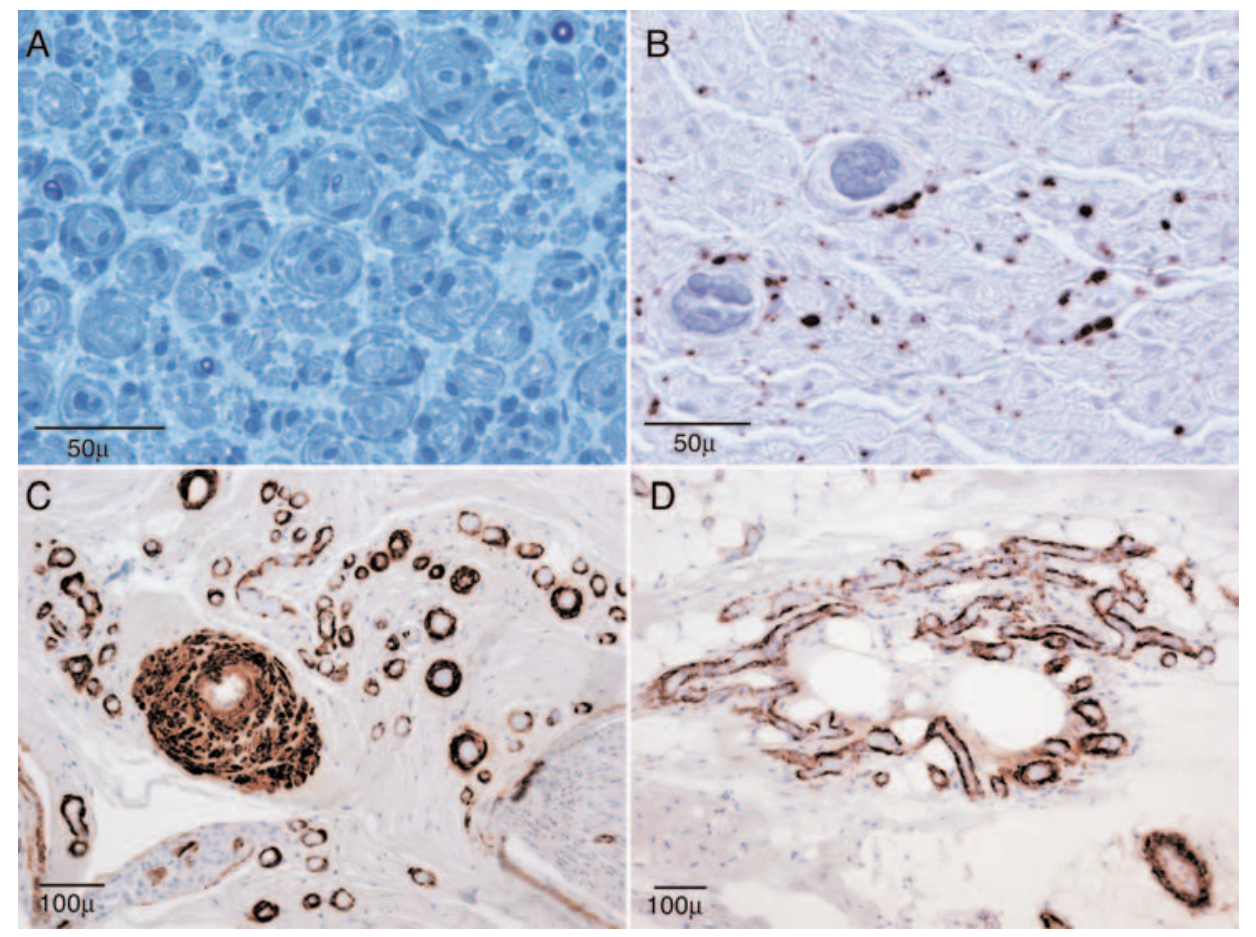

Figure 3. A left sural nerve biopsy from our patient with CMT1A and POEMS syndrome that shows extensive, large generalized hypertrophic onionbulbs in semithin epoxy sections stained with methylene blue (A). Note the severe decreased density of myelinated fibers with only a few remaining small thinly myelinated fibers. These findings imply a very chronic process and are consistent with CMT1A. An immunohistochemical preparation for macrophages (CD68) show scattered endoneurial reactivity often associated with onion-bulbs (B); whereas immunohistochemical preparations for smooth muscle actin shows extensive neovascularization of small epineurial vessels in cross $(C)$ and in longitudinal $(D)$ paraffin sections. This extensive neovascularization is typical of nerves from POEMS syndrome and is associated with increased levels of VEGF. 

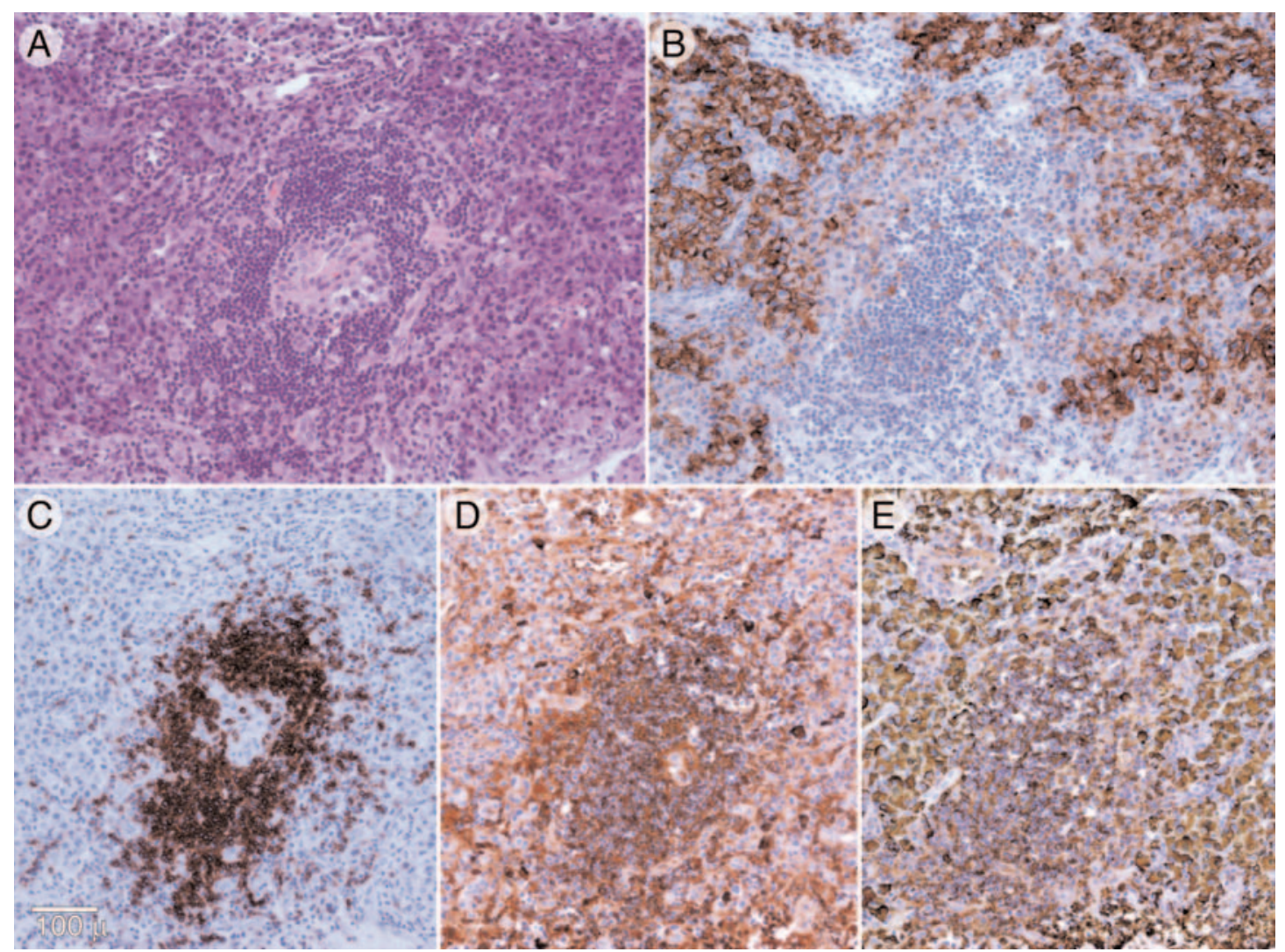

Figure 4. Serial paraffin sections from an axillary lymph node biopsy from our patient with CMT1A and POEMS syndrome showing a germinal follicle stained with $H \& E(A)$. The germinal follicle is surrounded by plasma cells at the peripheral (reactive to CD138) (B) and is composed of B-cells at the center (reactive to CD20) $(C)$. The surrounding plasma cells do not react to Kappa $(D)$ but do react to Lambda $(E)$ (the same cells that react to the plasma marker CD138 in panel $[B])$. These findings are consistent with Castleman's disease and Lambda light chain restriction.

Based on these evaluations, he was diagnosed as having both CMT1A and POEMS syndrome related to Castleman's disease. Because he had elevated VEGF levels, he was initially treated with bevacizumab $(5 \mathrm{mg} / \mathrm{kg}$, one dose every two weeks for three times); a recombinant humanized monoclonal antibody that binds to VEGF. With treatment, his VEGF levels normalized and his neurological symptoms stopped progressing. He then was treated with high dose melphalan and autologous peripheral blood stem cell transplantation (auto-PBSCT). At the time of the auto-PBSCT, he had profound weakness of all extremities and was confined to a wheelchair. At four months posttransplantation, he had marked neurological improvement and was able to ambulate with two canes and feed himself independently (which he had been unable to do previously).

Fourteen months after his auto-PBSCT, the patient was reevaluated at the Mayo Clinic and was found to be much improved - he could walk with ankle foot orthoses and could use his hands to dress and write. His neurological examination was much improved (NIS went from 121.5 to 64 points) and his severe proximal weakness had normalized. His nerve conduction studies were much improved (the conduction velocities, distal latencies and the trigeminal blink reflex latencies were not as slow or prolonged and the summated compound muscle action potential improved from 0.4 to 8.4 millivolts) and his needle examination showed less denervation (Table 3 ).

\section{Discussion}

This case illustrates that two independent causes may underlie the neuropathy of a single patient. In our patient, both inherited and acquired (myeloid dyscrasia) processes were responsible for the neurological manifestations and test abnormalities. This case also demonstrates that evaluating neurologists need to be able to recognize the clinical, electrophysiological and pathological features that are typical of different types of neuropathies in order to know when further testing is warranted.

Our patient clearly had CMT1A. He had PMP22 duplication consistent with CMT1A and a strong family history of CMT1A that fit an autosomal dominant inheritance. ${ }^{6}$ Other findings that were in keeping with inherited demyelinating neuropathy were his pes cavus deformity, uniform slowing of conduction 
Table 3: Nerve conduction studies/EMG after treatment

\begin{tabular}{llll} 
Nerve Conduction Study & & \\
\hline Stimulate (Record) & $\mathrm{A}(\mathrm{mV} / \mu \mathrm{V})$ & $\mathrm{CV}(\mathrm{m} / \mathrm{s})$ & $\mathrm{DL}(\mathrm{ms})$ \\
\hline R median sensory (Index) & 0 & -- & $\mathrm{NR}(<3.6)$ \\
R Musculocutaneous (BB) & 4.5 & 18 & 5.3 \\
R Ulnar motor (ADM) & $3.8(>6)$ & $24(>51)$ & $6.5(<3.6)$ \\
R Peroneal motor (TA) & 0.1 & 23 & 10.9 \\
R Sural sensory (Ankle) & $0(>6)$ & -- & $\mathrm{NR}(4.5)$ \\
\hline
\end{tabular}

Trigeminal Blink Reflexes

\begin{tabular}{llcccc}
\hline & & \multicolumn{2}{c}{ Ipsilateral } & \multicolumn{2}{c}{$\begin{array}{c}\text { Contralateral } \\
\text { R2 }\end{array}$} \\
\hline R Trigeminal supraorbital (OC) & 16.5 (8-13) & \multicolumn{2}{c}{$34.5(29-41)$} & $33.3(29-44)$ \\
\hline EMG & & & & & \\
\hline Muscle & Insertional & Fibrillation & & MUP & \\
\cline { 3 - 6 } & activity & & Recruitment & Duration & Amplitude \\
\hline R Biceps brachii & Increased & 0 & + & ++ & ++ \\
R FDI & Increased & + & ++ & ++ & ++ \\
R Medial gastroc. & Increased & + & +++ & ++ & ++ \\
R Tibialis anterior & Increased & + & ++ & +++ & ++ \\
R Vastus medialis & Increased & 0 & + & ++ & ++ \\
R Thoracic paraspinals & -- & 0 & ++ & ++ & + \\
\hline
\end{tabular}

velocities (on his early NCS/EMG), and diffusely distributed large onion-bulbs on nerve biopsy. Because CMT1A is a slowly progressive neuropathy with few or no positive neuropathic sensory symptoms (paresthesia), the sudden onset of positive neuropathic symptoms that rapidly and progressively worsened over the course of one year was very atypical for CMT1A. Patients with CMT1A who have episodes or acute worsening (stepwise or progressive) have been reported. ${ }^{1,7-13}$ It is thought that many of these patients may have a co-existing inflammatory component to their neuropathy, rather than a completely separate neuropathic process. Some of these cases had features more suggestive of an acquired disorder including conduction block, slowed F-waves and temporal dispersion on electrodiagnostic testing, markedly elevated CSF protein and inflammation in their nerve biopsies. This group has been reported to have a positive response to immunotherapy including steroids and has been termed "prednisone responsive" inherited neuropathy. ${ }^{7,9-12}$ Some authors have suggested that increased expression of PMP22 protein leads to an immune response against this protein and subsequently to additional genetic susceptibility to an inflammatory demyelinating neuropathy. ${ }^{10}$

The rapid and severe progression of our patient's symptoms lead us to look for another explanation than CMT1A and this investigation resulted in the diagnosis of POEMS syndrome related to Castleman's disease. Our patient meets the diagnosis criteria for the diagnosis of POEMS syndrome. ${ }^{3,4}$ He has mixed axonal and demyelinating polyradiculoneuropathy (polyneuropathy), lymphadenopathy (organomegaly), hypothyroidism, borderline diabetes mellitus, hypocalcaemia, and hypotestosterinism (endocrinopathies), IgA monoclonal protein (M-protein), and hypertrichosis and edema (skin changes). In addition, he has Castleman's disease or angiofollicular lymph node hyperplasia, a benign plasma cell proliferative disease. ${ }^{14-16}$
Ten to sixty percent of the POEMS patients have Castleman's disease. Castleman's disease has three variants, the hyalinevascular (HV) type, the plasma cell (PC) type and the mixed type. ${ }^{17}$ Peripheral neuropathy has been reported to be associated with the PC type ${ }^{18,19}$ and nerve biopsies may show small vessel proliferation in the epineurium as was seen in our patient. ${ }^{23}$ The pathogenesis of the neuropathy in Castleman's disease is unknown, but it has been postulated that it could relate to diffuse vasculopathy and increased VEGF levels. ${ }^{20-25}$ Our patient's serum VEGF level was moderately elevated and patients with levels $<1500 \mathrm{pg} / \mathrm{dl}$ tend to have a better prognosis. ${ }^{26}$

The best treatment for POEMS syndrome is probably high dose melphalan and autologous peripheral blood stem cell transplantation (auto-PBSCT). ${ }^{27-30}$ Our patient had a partial response to bevacizumab (a recombinant anti-VEGF antibody), as has been reported. ${ }^{31}$ However, he had marked and rapid neurological improvement to high dose melphalan and autoPBSCT. This marked neurological improvement provides a strong argument that most of his neurological deficits were secondary to his POEMS syndrome and not his CMT1A. However, much of the neurological impairment and electrophysiological abnormalities that remained after his autoPBSCT (distal weakness and uniform slowing of nerve conduction velocities in the range of $20 \mathrm{~m} / \mathrm{s}$ ) are typical of CMT1A and could be attributable to his inherited neuropathy.

Our case demonstrates that peripheral neuropathy can occur in one patient and be due to two separate pathophysiological mechanisms. Many of the clinical, electrophysiological and pathological features of our patient's neuropathy are due to CMT1A, whereas others are due to POEMS syndrome. Consequently, if the clinical features of a patient with an established neuropathy diagnosis are not in keeping with the features that are typical of that disease, then this patient needs a more intensive investigation for a second cause of the neuropathy. This case also demonstrates that correctly diagnosing the underlying etiology of a peripheral neuropathy is not just an academic exercise but has tangible effects on a patient's outcome. Because our patient was correctly diagnosed with POEMS syndrome (in addition to CMT1A), he underwent stem cell transplantation and subsequently went from wheelchair dependency to walking independently.

\section{ACKNOWLEDGEMENTS}

Supported in part by a grant obtained from the National Institute of Neurological Disease and Stroke (NINDS 36797).

The authors gratefully acknowledge Mary Lou Hunziker in the preparation of the manuscript. We thank Dr. Paul J. Kurtin for his evaluation of the lymphoid and bone marrow tissue and to Dr. Peter J. Dyck for editorial suggestions.

\section{REFERENCES}

1. Birouk N, Gouider R, Le Guern E, Gugenheim M, Tardieu S, Maisonobe T, et al. Charcot-Marie-Tooth disease type 1A with $17 \mathrm{p} 11.2$ duplication. Clinical and electrophysiological phenotype study and factors influencing disease severity in 119 cases. Brain. 1997;120(Pt 5):813-23.

2. Dyck PJ, Dyck PJB, Chalk CH. The 10 P's: A mnemonic helpful in characterization and differential diagnosis of peripheral neuropathy. Neurology. 1992;42:14-8. 
3. Dispenzieri A, Kyle RA, Lacy MQ, Rajkumar SV, Therneau TM, Larson DR, et al. POEMS syndrome: definitions and long-term outcome. Blood. 2003;101(7):2496-506.

4. Dispenzieri A. POEMS Syndrome. Hematology (Am Soc Hematol Educ Program). 2005:360-7.

5. Dyck PJ, Sherman WR, Hallcher LM, Service FJ, O'Brien PC, Grina LA, et al. Human diabetic endoneurial sorbitol, fructose, and myo-inositol related to sural nerve morphometry. Ann Neurol. 1980;8(6):590-6.

6. Lupski JR, de Oca-Luna RM, Slaugenhaupt S, Pentao L, Guzzetta V, Trask BJ, et al. DNA duplication associated with CharcotMarie-Tooth disease type 1A. Cell. 1991;66:219-32.

7. Dyck PJ, Swanson CJ, Low PA, Bartleson JD, Lambert EH. Prednisone-responsive hereditary motor and sensory neuropathy. Mayo Clin Proc. 1982;57:239-46.

8. Murakami T, Oomori H, Hara A, Uyama E, Mita S, Uchino M. Atypical phenotype of charcot-marie-tooth disease type 1A. Muscle Nerve. 1999;22(11):1593-6.

9. Malandrini A, Villanova M, Dotti MT, Federico A. Acute inflammatory neuropathy in Charcot-Marie-Tooth disease. Neurology. 1999;52(4):859-61.

10. Gabriel CM, Gregson NA, Wood NW, Hughes RA. Immunological study of hereditary motor and sensory neuropathy type 1a (HMSN1a). J Neurol Neurosurg Psychiatry. 2002;72(2):230-5.

11. Vital A, Vital C, Lagueny A, Ferrer X, Ribiere-Bachelier C, Latour $\mathrm{P}$, et al. Inflammatory demyelination in a patient with CMT1A. Muscle Nerve. 2003;28(3):373-6.

12. Ginsberg L, Malik O, Kenton AR, Sharp D, Muddle JR, Davis MB, et al. Coexistent hereditary and inflammatory neuropathy. Brain. 2004;127(Pt 1):193-202.

13. Carvalho AA, Vital A, Ferrer X, Latour P, Lagueny A, Brechenmacher C, et al. Charcot-Marie-Tooth disease type 1A: clinicopathological correlations in 24 patients. J Peripher Nerv Syst. 2005;10(1):85-92.

14. Castleman B, Towne VW. Case records of the Massachusetts General Hospital; weekly clinicopathological exercises; founded by Richard C. Cabot. N Engl J Med. 1954;251(10):396-400.

15. Castleman B, Iverson L, Menendez VP. Localized mediastinal lymphnode hyperplasia resembling thymoma. Cancer. 1956;9(4):822-30.

16. Dispenzieri A, Gertz MA. Treatment of Castleman's disease. Curr Treat Options Oncol. 2005;6(3):255-66.

17. Keller AR, Hochholzer L, Castleman B. Hyaline-vascular and plasma-cell types of giant lymph node hyperplasia of the mediastinum and other locations. Cancer. 1972;29(3):670-83.

18. Mallory A, Spink WW. Angiomatous lymphoid hamartoma in the retroperitoneum presenting with neurologic signs in the legs. Ann Intern Med. 1968;69(2):305-8.
19. Donaghy M, Hall P, Gawler J, Gregson NA, Leibowitz S, Jitpimolmard S, et al. Peripheral neuropathy associated with Castleman's disease. J Neurol Sci. 1989;89(2-3):253-67.

20. Watanabe O, Arimura K, Kitajima I, Osame M, Maruyama I. Greatly raised vascular endothelial growth factor (VEGF) in POEMS syndrome. Lancet. 1996;347:702.

21. Soubrier M, Dubost JJ, Serre AF, Ristori JM, Sauvezie B, Cathebras $\mathrm{P}$, et al. Growth factors in POEMS syndrome: evidence for a marked increase in circulating vascular endothelial growth factor. Arthritis Rheum. 1997;40(4):786-7.

22. Watanabe O, Maruyama I, Arimura K, Kitajima I, Arimura H, Hanatani $\mathrm{M}$, et al. Overproduction of vascular endothelial growth factor/vascular permeability factor is causative in CrowFukase (POEMS) syndrome. Muscle Nerve. 1998;21(11): 1390-7.

23. Dyck PJ, Engelstad J, Dispenzieri A. Vascular endothelial growth factor and POEMS. Neurology. 2006;66(1):10-2.

24. Nishi J, Arimura K, Utsunomiya A, Yonezawa S, Kawakami K, Maeno N, et al. Expression of vascular endothelial growth factor in sera and lymph nodes of the plasma cell type of Castleman's disease. Br J Haematol. 1999;104(3):482-5.

25. Nishi J, Maruyama I. Increased expression of vascular endothelial growth factor (VEGF) in Castleman's disease: proposed pathomechanism of vascular proliferation in the affected lymph node. Leuk Lymphoma. 2000;38(3-4):387-94.

26. Scarlato M, Previtali SC, Carpo M, Pareyson D, Briani C, Del Bo $\mathrm{R}$, et al. Polyneuropathy in POEMS syndrome: role of angiogenic factors in the pathogenesis. Brain. 2005;128: 1911-20.

27. Jaccard A, Royer B, Bordessoule D, Brouet JC, Fermand JP. Highdose therapy and autologous blood stem cell transplantation in POEMS syndrome. Blood. 2002;99(8):3057-9.

28. Dispenzieri A, Moreno-Aspitia A, Suarez GA, Lacy MQ, ColonOtero G, Tefferi A, et al. Peripheral blood stem cell transplantation in 16 patients with POEMS syndrome, and a review of the literature. Blood. 2004;104(10):3400-7.

29. Dispenzieri A, Gertz MA. Treatment options for POEMS syndrome. Expert Opin Pharmacother. 2005;6(6):945-53.

30. Kuwabara S, Misawa S, Kanai K, Kikkawa Y, Nishimura M, Nakaseko C, et al. Autologous peripheral blood stem cell transplantation for POEMS syndrome. Neurology. 2006;66(1):105-7.

31. Straume O, Bergheim J, Ernst P. Bevacizumab therapy for POEMS syndrome. Blood. 2006;107(12):4972-3; author reply 3-4. 